\title{
Plant ecology meets animal cognition: impacts of animal memory on seed dispersal
}

\author{
Elizabeth A. John • Francesca Soldati • Oliver H. P. Burman • \\ Anna Wilkinson - Thomas W. Pike
}

Received: 30 April 2016/ Accepted: 30 August 2016/Published online: 16 September 2016

(C) The Author(s) 2016. This article is published with open access at Springerlink.com

\begin{abstract}
We propose that an understanding of animal learning and memory is critical to predicting the impacts of animals on plant populations through processes such as seed dispersal, pollination and herbivory. Focussing on endozoochory, we review the evidence that animal memory plays a role in seed dispersal, and present a model which allows us to explore the fundamental consequences of memory for this process. We demonstrate that decision-making by animals based on their previous experiences has the potential to determine which plants are visited, which fruits are selected to be eaten from the plant and where seeds are subsequently deposited, as well as being an important determinant of animal survival. Collectively, these results suggest that the impact of animal learning and memory on seed dispersal is likely to be extremely important, although to date our understanding of these processes suffers from a conspicuous lack of empirical support. This is partly because of the difficulty of conducting appropriate experiments but is also the result of limited interaction between plant ecologists and those who work on animal cognition.
\end{abstract}

Communicated by Prof. Lauchlan Fraser, Dr. Chris Lortie and Dr. J. C. Cahill.

E. A. John $(\bowtie)$ · F. Soldati · O. H. P. Burman ·

A. Wilkinson - T. W. Pike

Joseph Banks Laboratories, School of Life Sciences,

College of Science, University of Lincoln, Green Lane,

Lincoln LN6 7DL, UK

e-mail: ljohn@lincoln.ac.uk
We believe that an improved understanding of the effects of animal memory in endozoochorous interactions will allow better prediction of the impacts of ecosystem changes such as habitat fragmentation, introductions of novel species of plants and animals and reintroductions of animal populations to areas from which they have been extirpated, and hope that the ideas we put forward here provide an impetus for further work in this area.

Keywords Animal behaviour · Frugivory - Animal learning - Animal memory seed dispersal . Endozoochory $\cdot$ Plant-animal interactions

\section{Introduction}

There is increasing concern over the impacts of defaunation of ecosystems on important mutualistic services such as seed dispersal and pollination, as well as predatory relationships such as herbivory, all of which can have profound impacts on plant population processes and resulting plant community composition and structure (Galetti and Dirzo 2013; RobledoArnuncio et al. 2014). To a large extent, the effects of these processes on plant population structures depend on decisions made by animals about which plants to feed from, how much to feed, when to move away and where to go next. However, our understanding of how these critical decisions are influenced by 
animals' learning and memory is underdeveloped, and plant ecologists could profit from working with animal cognition experts to develop more robust and predictive theory in this area. In this paper, we develop our ideas using endozoochory, the internal transport of seeds by animals, as an important mutualism (Fragoso et al. 2003; Guzmán and Stevenson 2011; Traveset et al. 2014; Wunderle 1997), and we introduce a model that allows us to specifically explore the implications of memory for seed dispersal.

Endozoochory is an important determinant of the population dynamics of many plant species. Seeds are generally inadvertently eaten by animals attracted by the fleshy fruit and dispersal occurs when the animal defecates or regurgitates at a location away from the parent plant. Endozoochory allows plants to escape the density-dependent effects of growing close to their parents (e.g. Harms et al. 2000; Howe and Miriti 2000; Janzen 1970; Muller-Landau and Hardesty 2005; Schupp and Jordano 2010; Wills et al. 1997) and to disperse to suitable microhabitats. Adaptations of plants for endozoochory are widespread, with up to $94 \%$ of woody species in some tropical rainforests producing the fleshy fruits attractive to vertebrate dispersers (Howe and Smallwood 1982; Jordano 2000; Tanner 1982). While few vertebrates are obligate frugivores, fruit contributes in varying proportions to the diets of many birds (it has been estimated, for example, that $50 \%$ of the biomass of birds in Panama is supported by fruit; Fleming et al. 1987), mammals and reptiles (Jordano 2000). Where endozoochory is disrupted by habitat fragmentation or loss of key species, significant ecosystem consequences are observed (Cordeiro and Howe 2003), such as reduced recruitment of plant species with particular ecosystem roles. Endozoochory is therefore considered a crucial ecosystem service that is both dependent on the maintenance of plant and animal biodiversity and helps to maintain it (Buckley et al. 2006; Fleming and Kress 2011; Garcia et al. 2013; Howe 1984; Howe and Miriti 2000).

The outcome of endozoochory (in terms of the number of seeds dispersed and their dispersal locations) relies on many interacting factors. The vegetation of an area affects assemblages of seed dispersers, as the number of frugivore species and individuals is correlated with habitat structure and local abundance of fruit (Tellería and Pérez-Tris 2003; Tellería et al. 2008; Gleditsch and Carlo 2011; Aparicio et al. 2013).
The abundance and density of frugivores in turn affects the rate of seed dispersal (González-Castro et al. 2015), so the availability of resources seems to be one of the primary factors regulating the number of seeds dispersed (Carlo and Morales 2008). The composition of frugivore assemblages is also important with factors such as the animal's metabolic rate and mobility influencing the number of seeds dispersed and their dispersal location (González-Castro et al. 2015). To date, much research on frugivores has focused mainly on observations of their behaviour, assessing their quality as dispersers on the basis of the amount of fruit eaten, the number of seeds processed, the number of viable seeds contained in faeces and the estimation of long seed dispersal distance based on data on animal daily movement and gut retention time (e.g. Calviño-Cancela and Martín-Herrero 2009; González-Castro et al. 2015; Jerozolimski et al. 2009; Link and Di Fiore 2006; Schupp 1993; Strong and Fragoso 2006). Although highly informative, this approach lacks predictive power in the face of ecosystem disruption because the cognitive determinants of the behaviour of seed dispersal vectors are largely unexplored. To address this, we need to evaluate the impact of animal knowledge, in terms of learning and memory, on which plants' fruit they eat and where they deposit seeds.

Locating and travelling to a particular fruit-bearing plant, selecting which fruit to eat, deciding when to leave and where to go next are all crucial decisions that will affect the fate of a plant's seeds and depend on the animal's cognitive abilities and prior knowledge. An animal first locates a fruit source in a number of ways. It can learn from other animals such as parents (Gopukumar et al. 2003), other conspecifics (Wilkinson et al. 2010) or heterospecifics (Tsuji et al. 2007). Alternatively, it may respond to cues that indicate the presence of fruit at some distance such as smell (Lomáscolo and Schaefer 2010; Siemers et al. 2007), sight (Cazetta et al. 2009) or the sound of other frugivores (Tsuji et al. 2007). Finally, it could locate the source serendipitously as it moves around the habitat.

Animals use a wide range of sensory faculties to detect specific features that allow recognition of food sources (Wilkinson and Huber 2012). Many studies have examined how fruit traits such as colour, scent and shape are used by animals as indicators of nutrient content and ripeness of fruits (e.g. Cazetta et al. 2009, 2012; Schaefer 2011; Schaefer et al. 2003, 2004), 
and cognitive studies have confirmed that animals possess the discriminatory skills to differentiate successfully on the basis of such cues; animals can, for example, discriminate relevant colours (Dominy et al. 2003; Kelber et al. 2007), shapes (Gosset and Roeder 2000), smells (Hübener and Laska 2001) and textures (Dominy et al. 2001). Thus, it is generally accepted that sensory features of fruit play a fundamental role in attracting frugivores and are used by animals to select fruit for eating (Schaefer et al. 2004). However, the role of previous experience and its impact on food choice is poorly explored (although see Schaefer et al. 2008). Further, we have very little basis for making predictions about the impact of disperser learning and memory on resultant endozoochory, whether in terms of quantity of seeds dispersed, which seeds are dispersed or where the seeds are deposited.

An animal's memory, which results from its individual experiences, is likely to influence every aspect of its role as a seed disperser. In order to use information efficiently, the animal not only has to acquire it, but needs to retain it and retrieve it appropriately. Multiple factors influence memory in animals; however, there is evidence that some species, at least, have an efficient long-term memory which allows them to recall specific events and associate appropriate responses to those events (Fagot and Cook 2006). As a seed disperser, an animal might remember information about the locality of fruiting plants (such as location, ease of access, presence of predators or competitors), the quality and quantity of fruit produced (both in absolute terms and relative to other nearby plants), the timing of fruit production and the location of other nearby resources such as water, shelter or sun gaps for reptiles. Each of these could contribute to the population dynamics of an individual plant, determining how many of its seeds are dispersed, by which species of frugivore and where they are then deposited. Many animals are postulated to use cues from more knowledgeable conspecifics (e.g. elephants (Blake et al. 2009; Polansky et al. 2015; Foley et al. 2008) or from heterospecifics (Saracco et al. 2004) to help them identify and navigate to resources or may follow trails left by conspecifics (e.g. Blake and Inkamba-Nkulu 2004). Differences between individuals in quality and quantity of memory might arise due to species-specific cognitive capabilities, previous experience or individual longevity. The presence of other animals with better or worse knowledge of the local habitat could have a significant impact on the outcome of foraging by a focal animal.

The knowledge that animals hold about their environment will depend on many factors (including species and individual experience) and vary in quality. Learning and memory are metabolically costly (Burns et al. 2011; Mery and Kawecki 2005) and medium- to long-term memory of resource location may only have value greater than its cost in environments where resources are patchily and predictably distributed (Bracis et al. 2015; Eliassen et al. 2009). As fruit is usually patchily distributed in space and time (Fleming et al. 1987) but often recurs in the same location at relatively long but predictable periods, we might predict that long-term memory would be adaptive for frugivores. However, as individual animals will have different experiences, they will also have different memories. Further, there is growing evidence to suggest that the strength of a memory is influenced by the animal's affective state at the time of memory formation such that very positive or negative events are remembered more strongly than more neutral events (Mendl et al. 2001). This could mean that excellent food sources will be remembered for longer and prioritised (e.g. Ban et al. 2014) or that a close encounter with a predator would deter an animal from revisiting a food source.

We would also predict that natural or anthropogenic habitat alteration might impact an animal's ability to navigate to or locate a previous food source. Animals immigrating into or relocated to a new area will have no knowledge of the area and its plants. Animals being used as functional equivalents in rewilding or restoration projects (Griffiths et al. 2010; Hansen et al. 2010) might have different cognitive skills and so make different choices from the species they are replacing. Local extinctions of species or loss of fruiting individuals (for instance, the removal of large fruiting trees), invasions by non-native species, phenological changes in fruiting patterns or loss of predictable seasonality due to climate change (Chapman et al. 2005; Corlett and Lafrankie 1998) could all be expected to disrupt and confuse existing frugivores even when they remain present in the community, with consequences for their decision-making.

In this context of environmental change, it is useful to understand how animals are likely to navigate within a familiar environment. Generally, animals rely on external stimuli as a basis for orientation. A simple 
but effective strategy is the use of a distinctive cue located near the goal (e.g. López et al. 2001). This is then used as a beacon upon which an animal can home. Loss of such a stimulus (e.g. a prominent tree acting as a landmark) results in inability to access remembered resources even when close to them (e.g. López et al. 2001). A more complex but flexible system is the use of a cognitive map in which the goal is defined by its spatial relation to a number of landmarks (O'Keefe and Nadel 1978), thus the loss of a single landmark does not alter success; however, the loss of multiple cues in a disrupted habitat could result in an animal failing to return successfully to a resource. This is considered a highly efficient navigational mechanism that allows an animal to cope with some environmental change; however, it imposes a high burden on memory load (Dale and Innis 1986). Alternatively, animals can navigate using a response-based strategy in which a goal is reached by performing a specific sequence of responses (e.g. Wilkinson et al. 2009). With a strategy of this kind, no external cues are needed to reach the goal successfully, and thus it does not place a burden on memory. However, such an inflexible system cannot adapt to any changes in the external environment and is normally observed in conjunction with other mechanisms (Bond et al. 1981). These insights into how animals locate and relocate resources help us understand the potential consequences for plant-animal interactions of ecosystem disruption and suggest avenues of investigation with particular groups of frugivores that will aid us in understanding the consequences for endozoochory.

We believe that plant ecologists should work with animal cognition experts to start to understand the effect of animal memory on seed dispersal by frugivores. A better understanding of this area would also help us predict the impact of factors that impair an animal's ability to navigate in a habitat, such as physical ecosystem disturbances or the introduction of naive animals to a novel habitat. The aim of this paper is to highlight one aspect of animal cognition and memory that can help to better understand the seed dispersal process, and to indicate areas where we believe that the disciplines of plant ecology and cognition can profitably interact. Specifically, we consider three main predictions, all of which could have significant impacts on the number of seeds dispersed from an individual plant, the relative success of seed dispersal from separate plants and the locations to which seeds are dispersed, and yet all of which have received little theoretical or empirical attention:

1. Whether or not a seed-dispersing animal can remember and relocate a fruiting plant affects their movement patterns and, as a consequence, the distribution of plants' seeds.

2. A seed disperser's memory of individual plant quality affects their service provision to plants of different qualities.

3. Memory of the location of non-food resources, and the motivation to move towards them, will affect the pattern of seed deposition.

In addition to exploring these ideas by evaluating available information, we also developed a model to allow us to make specific predictions regarding the impact of disperser memory on seed dispersal. This model is based on a combination of the perception and memory-based movement model described by Avgar et al. (2013) and the seed dispersal model of D'hondt and Hoffmann (2011). Full details are given in Appendix 1, although the salient points are summarised below.

\section{Model overview}

We consider an animal characterised by a single parameter, state, which we equate to hunger; when the value of the state parameter is low, we consider the animal to be relatively hungry, and when it is high the animal is relatively sated. This animal inhabits a landscape, each cell of which is characterised by the values of two habitat components: the background landscape and the vegetative landscape. Higher values are more attractive to the animal (for example, indicating more food, preference for landscape features such as shelter) and lower values are less attractive (for instance, less food, unpreferred habitat type). The animal moves stochastically around this landscape in a state-dependent manner, during which it ingests, defecates and disperses seeds. Specifically, we assume that it assesses the quality of surrounding cells using sensory information, which attenuates with distance (perception) and accumulates over time (memory) and which it uses to guide its movement. Key to our model is the rate at which an animal's memory decays, which is encapsulated by the memory decay coefficient $\beta(\beta \geq 0)$. When $\beta=\infty$, decay is 
instantaneous and so the animal has no memory other than what can be currently perceived; when $\beta=0$, there is no decay and the animal retains in its memory all previously perceived information; when $0<\beta<\infty$, memory decays exponentially over time. Note that by taking values of $\beta$ in the interval $[0, \infty)$, the values of the term $e^{-\beta}$ are distributed in the interval $[0,1]$. The term $e^{-\beta}$ can therefore be interpreted as an animal having perfect $\left(e^{-\beta}=1\right)$, intermediate $\left(0<e^{-\beta}<1\right)$ or absent $\left(e^{-\beta}=0\right)$ memory; for convenience, we refer to this term throughout as 'memory'.

We ran two types of model. The first was parameterised with arbitrary values in order to explore the generic impact of memory on seed dispersal in landscapes with one or two plants. The second was parameterised using data on the behaviour and memory of red-footed tortoises (Chelonoidis carbonaria) in simulated natural landscapes in order to explore the specific impact of landscape use (in particular, the use of gaps in the forest canopy as basking spots) on the pattern of seed dispersal.

\section{Impact of memory on seed removal from a single plant (prediction 1)}

We used the model to investigate the impact of memory on the dispersal of seeds from a single food source at the centre of a landscape containing a single animal seed disperser initially located at the food source. In the model, the number of seeds dispersed in the environment increased with the amount of memory retained by an animal (Fig. 1). It is striking that in our model the impact of memory was far from linear, and that very high levels of memory had a disproportionate effect on the number of seeds dispersed. There was very little difference between perfect and near-perfect memory; however, medium levels were almost as ineffective as low levels. Because of this stark dichotomy between near-perfect memory and lower levels of memory, we next compared the effects of perfect versus no memory on the number of visits to the plant, the average seed dispersal distance and the survival time of the disperser.

In our model, the number of visits to the food source was significantly higher in animals with perfect memory than those with no memory $\left(F_{1,196}=7335.6\right.$, $p<0.001$; Fig. 2b). This was driven by the fact that after moving away from the food source, model animals with perfect memory were able to relocate it much more efficiently than those with no memory, resulting in a significantly higher number of seeds dispersed $\left(F_{1,196}=972.3, p<0.001\right)$; in contrast, animals with no memory had to rely on random exploration of the landscape to relocate one food source.

If ripe fruits are not consumed by an endozoochorous frugivore, plants risk seed damage and mortality due to fruit predation by a non-dispersing frugivore or granivore (Bonte et al. 2011). If, as the model predicts, animals with good memory visit a plant more frequently, this would result in greater service to the plant (Schupp et al. 2010) and reduced costs associated with the loss of seeds due to seed predators or the possibility that seeds will remain under the parental tree. However, from the plant's perspective the quality of the dispersal service depends not only on the number of seeds dispersed but also on where the seeds are dispersed to. Consistent with the greater amount of habitat exploration a lack of memory necessitated, the median dispersal distance was significantly higher in model animals with no memory than in animals with perfect memory $\left(F_{1,196}=66.2, p<0.001\right.$; Fig. $\left.2 \mathrm{a}\right)$. This result would lead to the hypothesis that naïve animals exploring a habitat for the first time, or dispersing through a habitat, may be particularly important in providing opportunities for rare, long-distance dispersal events, while animals with good memory are important for bulk dispersal of large numbers of seeds within a constrained spatial envelope.

Finally, in our model, animal longevity was significantly impacted by memory: animals with no memory tended to die after relatively few time steps (curtailing their capacity for seed dispersal), while animals with full memory invariably survived for the full run of the model (survival analysis: $\chi^{2}(1)=1962.5, p<0.001$; Fig. 2c, Bracis et al. 2015). This confirms the immense value of memory for animals living in environments with patchily distributed resources (Boyer and Walsh 2010). While this initial simple model allows us to build hypotheses about the importance of frugivore memory for seed dispersal, in ecological situations there will rarely be a single fruit source and a single disperser. Below we extend the model to explore the impact of animal memory on dispersal from competing trees of differing quality. 
Fig. 1 a Quantity of seeds dispersed (arbitrary units) as a function of the dispersers' memory, which could vary between 0 (no memory) and 1 (perfect memory). Each data point represents one run of the model.

b Representative seed shadow from an animal with perfect memory and $\mathbf{c}$ an animal with imperfect memory

(memory $=0.047)$. A single plant was located at the centre of each landscape
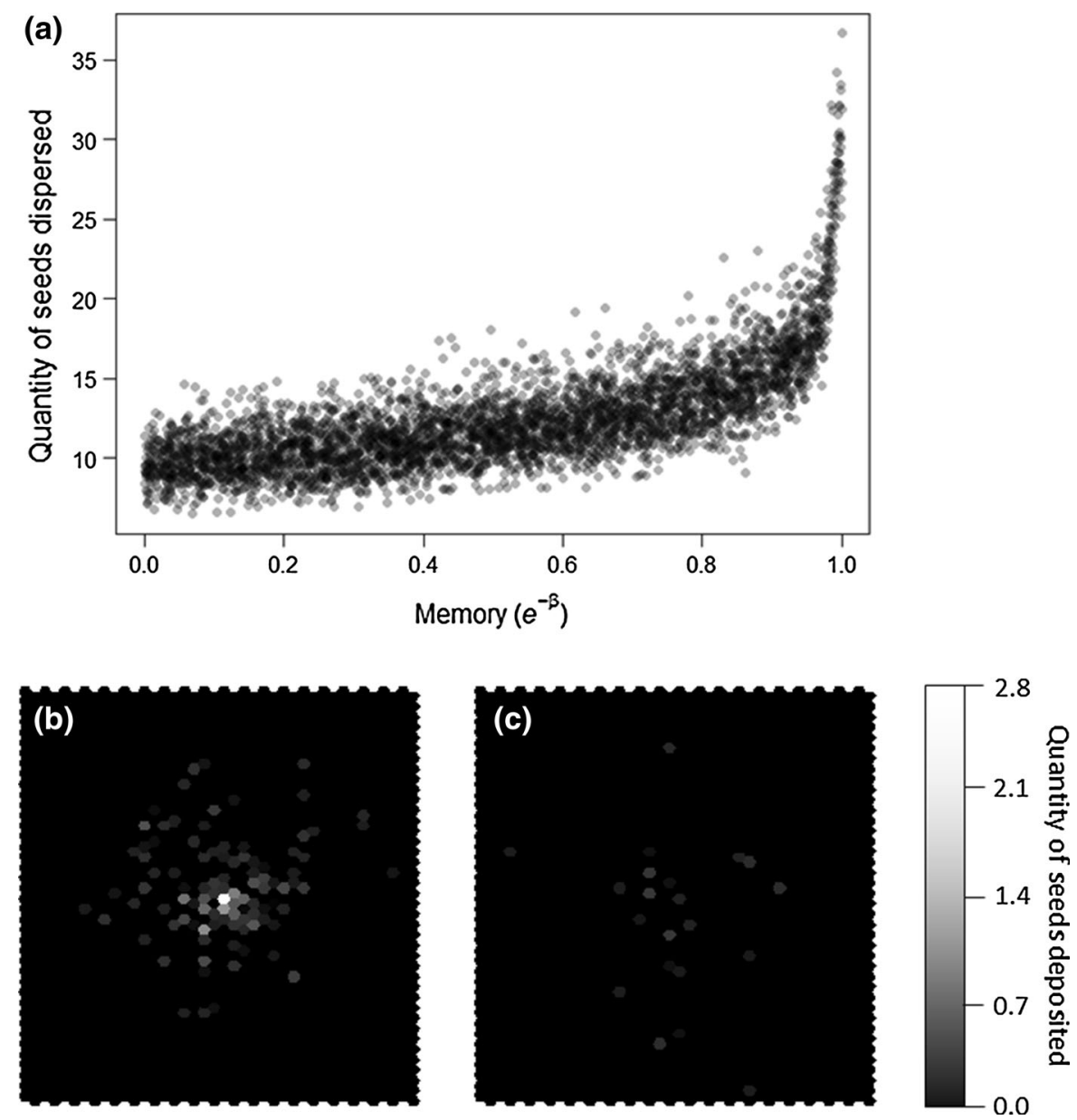

\section{Impact of memory on service to each of two competing plants (prediction 2)}

Endozoochory often occurs in complex and biodiverse environments. For instance, a single fruiting fig in a tropical forest may attract numerous species of frugivores, including primates, bats and birds, and in fact most endozoochory is polychorus (Jordano et al. 2003). Ground-dwelling frugivores such as ungulates and tortoises may eat fruit that falls, although they will face different challenges from arboreal animals in identifying and locating the food source. While these animals may compete with each other and with many non-dispersing fruit and seed predators for the available fruit, there will be situations when the plant is competing with other plants for the attention of appropriate frugivores (Fig. 3).

We used our model to explore the simplest case of two plants competing for the service of a single frugivore, endowed with either no memory or perfect memory, as above. By varying the relative quantity of fruit provided by each of the two trees, we identified a significant interaction between memory and the difference in quantity of food provided on the difference in quantity of seeds dispersed $\left(F_{1,996}=66.2, p<0.001\right.$; Fig. 3$)$ : when the animal had no memory, both plants received very similar levels of service, and the effect on the difference between the plants was very small; when the animal had perfect memory, it discriminated more between the two plants, giving much higher levels of service to the plant with the highest quantity of fruit. This result suggests that the memory of a frugivore could play a significant role in the outcome of competition for dispersal of two plants. It implies that a smaller plant providing less reward than a neighbour would receive disproportionately lower levels of service relative to a neighbour from a frugivore with good memory, while 

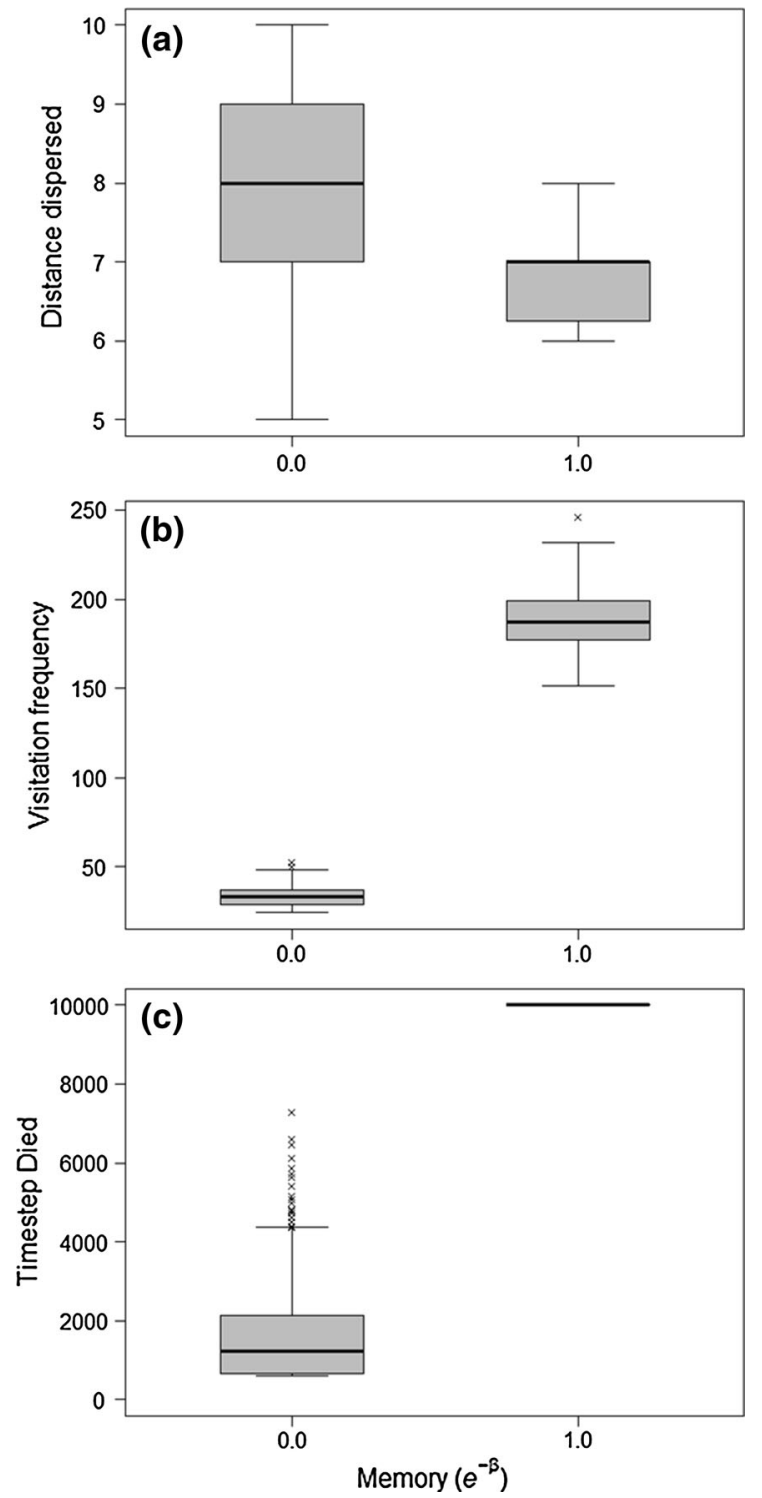

Fig. 2 Median, quartiles and range of a seed dispersal distance (in units of hexagonal Manhattan distance), b plant visitation frequency and $\mathbf{c}$ the number of time steps until death occurred, as a function of memory (where 0 denotes no memory and 1 denotes perfect memory). Outliers are denoted by a cross

a frugivore with poor memory would service the plants more equally. This in turn suggests that the contribution of two plants to the seeds being dispersed in a habitat will not be proportional to their reproductive effort if the dispersers are knowledgeable and have a choice of plants. Although we were modelling frugivory, it is reasonable to expect similar effects of animal memory on any competition between two

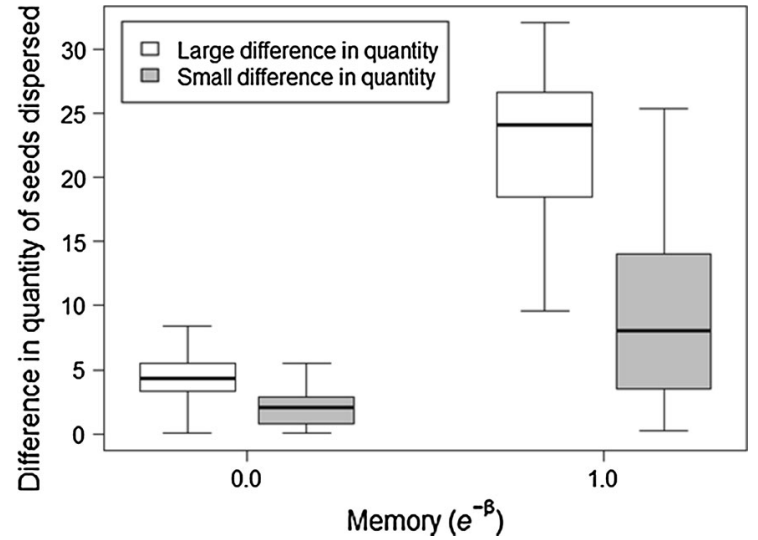

Fig. 3 Median, quartiles and range of the absolute difference in the quantity of seeds dispersed between two plants in the landscape (in arbitrary units), as a function of memory (where 0 denotes no memory and 1 denotes perfect memory) and the relative difference in the quantity of food available at each plant, quantised here as a relatively large (white boxes) or relatively small (grey boxes) difference based on whether they fell above or below the overall median difference

plants for an animal service and so these results could also apply to pollination.

We know that animals are capable of learning about the quantity and quality of food sources in experimental situations (Soldati 2015). We know less about how they make choices in complex field environments, where quality and quantity will vary. Animals can retain information on previous feeding experiences, such as the taste (Yarmolinsky et al. 2009) and digestive feedback (Werner et al. 2008; Yearsley et al. 2006), and there is an increasing body of evidence that some animals can remember the locations of the food and other resources and have the skills to navigate back to them (Janmaat et al. 2013; Blake and InkambaNkulu 2004). We also know that in experimental situations animals will demonstrate a preference for one fruit over others. However, in the wild, many frugivores have a mixed diet (Guzmán and Stevenson 2008; Moskovits and Bjorndal 1990) and it is difficult to find a correlation between fruit eaten and fruit preferences reported in experiments (Carlo and Morales 2008). This could be because frugivores respond to their nutritional needs (Murphy and King 1987), tending to balance their nutrient intake (McCaughey and Tordoff 2002). Thus, their choice of food could be driven by immediate needs for particular nutrients rather than exclusively by their innate or learned preferences. Optimal foraging theory 

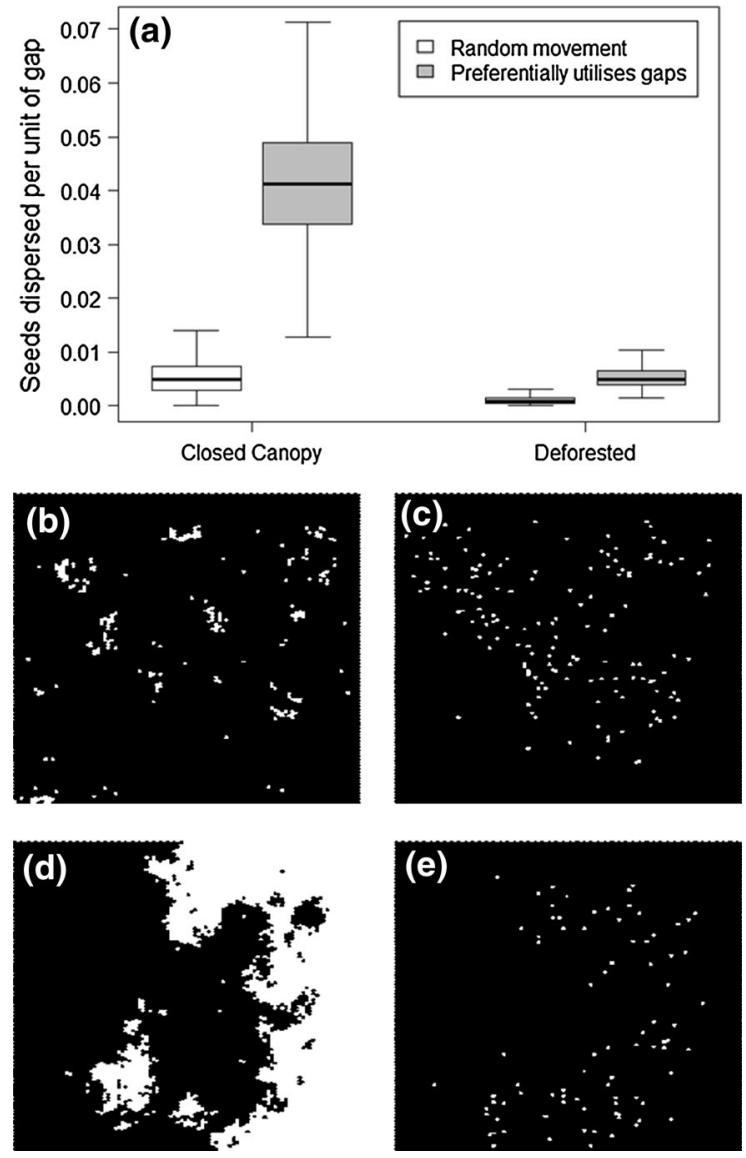

Fig. 4 a Median, quartiles and range of the number of seeds dispersed per unit of gap, in animals with nearly perfect memory (Appendix 1) that preferentially utilise gaps (grey boxes) (in this case, modelled on red-footed tortoises) and animals that utilise gaps at random (white boxes), in both closed canopy and deforested landscapes. Representative examples of a closed canopy landscape b and associated seed distribution pattern resulting from the movement of animals that preferentially utilise gaps $\mathbf{c}$, and a deforested landscape $\mathbf{d}$ with associated seed distribution pattern $\mathbf{d}$. In $\mathbf{c}$ and $\mathbf{e}$, white locations indicate the presence of seeds

predicts that animals will select a food source according to the associated costs and benefits (Kacelnik and Houston 1984; Pyke 1984). The quantity and quality of food potentially obtained at each foraging event (benefits) are traded off against costs, such as the energy required to reach to the food source (Levey et al. 1984), and perceived predation risk or competition (Kacelnik and Bateson 1996; Kacelnik et al. 2013). For example, tanagers and manakins (P. mentalis, $M$. candei) change their likelihood of feeding on less preferred food when the distance between perches increases (Levey et al. 1984); and Steller's Jays (Cyanocitta stelleri) modify their food choice depending on the presence of other conspecifics in the feeding area (Bekoff et al. 1999).

Clearly, many factors will impact on which of two competing plants receives the most benefit from seed dispersers, but our model's results suggest that the quality of memory of the seed disperser could be an important contributor to seed dispersal outcomes. Only animals that actually remembered about the food sources were able to produce a significant difference in terms of fruit removal between two plants of different value. An animal foraging multiple times from one plant while ignoring others would give that plant an advantage in terms of seed removal (Boyer and LópezCorona 2009). Carlo and Morales (2008) and Aparicio et al. (2013) suggested that the rate of seed removal depends in particular on the number of frugivores present in a certain area. While this is certainly true, it is possible that high-quality plants in an environment with fewer seed dispersers equipped with good memory skills might receive a better fruit removal service than plants in an environment with a larger number of frugivores with lower memory skills. On the other hand, a lower quality plant competing for service with higher quality plants might benefit from more frugivores with poorer memory skills.

\section{Seed dispersal depends on motivation to move to other resources (prediction 3)}

The motivation for an animal to move away from a fruit source once it has fed and where it next travels may be as critical to the effectiveness of a seed dispersal event as the original decision to feed from a plant (Schupp et al. 2010). Failure to move away from the parent plant before defecation will not result in effective dispersal, nor will deposition of seeds in a distant but unsuitable location. Either of these scenarios would be costly for the plant (Bonte et al. 2011).

There are many possible motivations for an animal to move away from a fruit source, each of which could impact on the next destination of the animal and the potential deposition site of the seeds. The frugivore may have exhausted the food supply, or lowered the density of fruit to the point where the benefits of feeding no longer outweigh the costs of continuing to forage there. It may have been disturbed by 
competitors or predators, making the environment seem less safe or more difficult to forage in. It may be satiated or sufficiently satiated that another resource or need (e.g. water, mates, shelter, basking) becomes more salient. Understanding these motivations and how they interact with frugivore knowledge and memory is important in predicting the seed shadows of plants. In our model, we introduced landscape patchiness to simulate non-foraging areas that would be attractive (or otherwise) to a seed disperser. Specifically, we assumed that the landscape features represented forest gaps which acted to vary the motivation of animals, for example reptilian frugivores, to move towards sun patches in simulations of natural and deforested landscapes. We found that animals that were motivated to move towards the landscape gaps deposited more seeds in those areas than animals that moved around the landscape at random (Fig. 4a), but that this was highly dependent on the landscape (Fig. 4a-c) with a significant interaction between the animal's preference for utilising gaps and the landscape type $\left(F_{1,3996}=5785.7\right.$, $p<0.001)$.

While unsurprising, these results strongly indicate the importance of understanding animal motivation as well as memory. Ecological studies have typically relied on seed dispersal kernels-dispersal curves created by combining together data on daily animal movement and gut passage time (Westcott et al. 2005) — to estimate the dispersal distance that can be achieved by seeds, but no other information about the location of deposition. Knowing whether and which paths animals are likely to take can help predict the distance and quality of the deposition sites, allowing more precise estimations of seed shadow and potential for seedling establishment (Wang and Smith 2002). In addition, knowing whether a seed disperser regularly returns to an individual fruit tree or consumes fruit from a number of different trees randomly encountered during foraging would impact very differently on dispersal dynamics of a tree population (Jordano et al. 2007).

Seed dispersers that follow regular and predictable routes will have a very different impact on seed deposition patterns than dispersers that follow idiosyncratic or unpredictable routes (e.g. Moskovits and Kiester 1987). The latter would be more likely to find new food sources and increase the probability that seeds would be transported and deposited in new areas, but leading to unpredictable seed shadows (Boyer and López-Corona 2009) with wider spatial spread. Frugivores that tend to repeatedly visit the same areas and follow the same paths would create seed shadows with less spread than the one originated by random movement, creating areas where the density of seeds might be high (Boyer and LópezCorona 2009; Blake and Inkamba-Nkulu 2004). A number of recent studies have focussed on frugivores' spatial memory capabilities and travel patterns ( $\mathrm{Di}$ Fiore and Suarez 2007; Normand et al. 2009; Noser and Byrne 2010; Janmaat and Chancellor 2010). Di Fiore and Suarez (2007) found that over 8 years, spider monkeys (Ateles belzebuth) and woolly monkeys (Lagothrix poeppigii) tended to follow repeatedly the same path between fruit trees when foraging, which limited the dispersal of seeds to specific areas where seed density was high. Similarly, Tamarins (Saguinus fuscicollis weddelli) visited food sources in a spatially efficient manner, minimising the distance between foraging points (Porter and Garber 2013), suggesting that the tamarins retained information on either the specific or relative locations of the fruit trees to one another. This also resulted in predictable seed deposition with areas of high seed density along the paths connecting food sources used by tamarins. Elephants appear to form permanent trails connecting areas with high densities of fruit trees (Blake and Inkamba-Nkulu 2004), which may help guide naïve animals to food sources, but could also influence seed dispersal patterns (Blake et al. 2009). Therefore, knowing about animals' spatial memory skills and understanding how these might influence their movements through the environment could help predict the structure of future plant communities.

\section{Other aspects of memory for consideration}

While we have considered above the importance of the ability of seed dispersers to remember the spatial location of a food source, return to it and then move away, another cognitive skill that could be important in determining the quality of dispersal service provided by an animal is its ability to remember when fruit might be available in particular locations. Plant fruiting cycles are usually predictable in time, either according to fixed calendar intervals or following specific seasonal events such as a rainy season 
(Momose 2004; Moskovits and Bjorndal 1990). We hypothesise that being able to learn about when plants are likely to bear fruit will be as adaptive for a longlived frugivore as retaining spatial information about a food source, as it would allow them to forage more efficiently. This, in turn, would make them more effective seed dispersers, at least for known and favoured sources which would receive rapid seed removal when the fruits are ready to be eaten, decreasing the chances that early fruits would be consumed by seed predators or remain under the parental tree. It is likely to be particularly critical during periods of fruit shortage in the rainforest, such as in months when very few plants carry fruits (Chapman et al. 2005; Janmaat et al. 2014).

There is much evidence that shows animals are able to anticipate food-related events on diurnal or shorter time scales. For example, hummingbirds revisit flowers at the same rate as they re-fill with nectar (Henderson et al. 2006), honey bees forage at the time of the day when nectar concentration is highest (Corbet and Delfosse 1984) and many animals are able to use circadian cycles to anticipate daily food provisioning events (Biebach et al. 1989; Daan and Koene 1981; Roberts 2002).

However, these are on relatively short time scales and it remains unclear whether frugivores are actually able to anticipate the time and duration of the presence of ripe fruits on trees at seasonal time scales. Our recent work (Soldati 2015) suggested that not only they are to anticipate events on a circadian cycle, but also to learn about cues in the environment that predicted the food delivery events. This implies that animals might be able to learn about a range of salient environmental cues, such as the seasonal changes in temperature, as an indication of imminent presence of food. Grey-cheeked mangabeys (Lophocebus albigena johnstonii) tended to revisit fruiting trees more frequently after warm periods than after cold ones (Janmaat et al. 2006), and it is possible that mangabeys use higher temperatures as an indicator that fruit may be ripening. Honey bees also showed activity consistent with anticipating an increased food supply after appropriate weather conditions (Moore et al. 2011). Animals that are able to use environmental cues to anticipate the presence of food, such as ripe fruits, could benefit from the advantages of more efficient foraging as well as potentially reaching the food source before competitors. Plants, in turn, could benefit from knowledgeable and efficient frugivores removing ripe fruits, rapidly preventing fruits from decomposing under the parental tree where the mortality rate is higher or being eaten by seed predators. Therefore, animal anticipatory skill would improve seed removal and increase the quantity of seeds dispersed by legitimate seed dispersers, enhancing the reproductive success of trees as well as providing survival benefit to the animal. This highcost long-term memory might, however, become disadvantageous to animals and plants in situations where temporal fruiting patterns are changing due to climate change (Chapman et al. 2005; Corlett and Lafrankie 1998) or other causes.

\section{Conclusion}

A fuller understanding of the cognitive mechanisms underlying the behaviour of frugivores will bring new insight and help build more reliable predictions of seed dispersal by endozoochory (Corlett 2011; Cousens et al. 2010) in stable and changing environments, ultimately allowing us to better predict the consequences of change for plant population dynamics (Robledo-Arnuncio et al. 2014). Here we have provided evidence that animal memory has the potential to influence many aspects of seed dispersal, including the number of seeds dispersed, the distance to which they are taken, the locations where they are deposited and the relative dispersal of two competing species. The ultimate effects of animal memory in more complex and realistic environments have yet to be elucidated, but laboratory experiments and models such as the one presented here can offer insight and hypotheses to test. Further insight can be gained by parameterising models with data on specific animals' cognitive abilities and movement patterns as well as increasing the level of environmental complexity they simulate. Although it is hard to manipulate animal memory in the field, we believe that the opportunities afforded by reintroductions, invasive species and rewilding efforts (Griffiths et al. 2010) may be very valuable, allowing us to understand how animals with no local knowledge of the ecosystem and/or different cognitive abilities from native species will impact plant populations. We could also exploit disrupted ecosystems to examine the impacts of disturbance on the ability of animals to remember and navigate to key 
resources and the subsequent impacts on plant population dynamics. We believe that the principles outlined in this paper apply to most ecosystem processes where plant-animal interactions are important including pollination and herbivory as well as seed dispersal. We can see the potential for many exciting and important collaborations between plant ecologists and experts in animal cognition and urge closer working.

Acknowledgments We acknowledge the support of a studentship awarded to Francesca Soldati by the School of Life Sciences, University of Lincoln, and we thank Ana Mariscal for sharing her forest gap data.

Open Access This article is distributed under the terms of the Creative Commons Attribution 4.0 International License (http:// creativecommons.org/licenses/by/4.0/), which permits unrestricted use, distribution, and reproduction in any medium, provided you give appropriate credit to the original author(s) and the source, provide a link to the Creative Commons license, and indicate if changes were made.

\section{Appendix 1}

This model is based on a combination of the perception and memory-based movement model described by Avgar et al. (2013) and the seed dispersal model of D'hondt and Hoffmann (2011).

\section{The seed disperser}

We consider an animal characterised by a single parameter, state $s(0 \leq s \leq 1)$, which we equate to hunger; when $s$ is low, we consider the animal to be relatively hungry, and when $s$ is high the animal is relatively sated. During each of $T$ discrete time steps $t(t=1,2, \ldots, T)$, this animal moves stochastically around a landscape, $A$, in a state-dependent manner, during which it ingests, defecates and disperses seeds.

\section{Perception, memory and assessment of habitat quality}

The landscape is modelled as a heterogeneous hexagonal grid of cells, $i$ (Avgar et al. 2013). Each cell is characterised by its spatial coordinates and the values of two habitat components, the background landscape $\left(A_{i, 1}\right)$ and the vegetative landscape $\left(A_{i, 2}\right)$, each taking values in the interval $[0,1]$. Higher values are more attractive to the animal (for example, indicating more food, preference for landscape features such as shelter) and lower values are less attractive (for instance, less food, unpreferred habitat type). We assume that the animal assesses the quality of surrounding cells using sensory information, which attenuates with distance (perception) and accumulates over time (memory). At time step $t$, the animal's perception, $p(0 \leq p \leq 1)$, of cell $i$ for a given layer $j$ of the landscape is

$p_{i, j, t}=A_{i, j} e^{-\alpha d_{i}}$,

where $d$ is the (hexagonal) Manhattan distance from the animal's current location to cell $i$ and $\alpha(\alpha>0)$ is the sensory attenuation coefficient. The term $e^{-\alpha d_{i}}$ therefore describes the proportion of information perceived at distance $d$; when $d=0$ (i.e. cell $i$ is occupied by the animal), the animal has perfect perception, with the proportion of information perceived declining exponentially with increasing $d$. This sensory information is subsequently committed to the animal's memory, $m(0 \leq m \leq 1)$, which decays with time such that

$m_{i, j, t}=p_{i, j, t}+\left(1-e^{-\alpha d_{i}}\right)\left(m_{i, j, t-1} e^{-\beta}\right)$,

where $\beta(\beta \geq 0)$ is the memory decay coefficient, which models the proportion of information retained in the memory. When $\beta=\infty$, decay is instantaneous and so the animal has no memory other than what can be currently perceived; when $\beta=0$, there is no decay and the animal retains in its memory all previously perceived information; when $0<\beta<\infty$, memory decays exponentially over time. Note that the values of $\beta$ in the interval $[0, \infty)$ mean that the values of the term $e^{-\beta}$ are distributed in the interval $[0,1]$. The term $e^{-\beta}$ can therefore be interpreted as an animal having perfect $\left(e^{-\beta}=1\right)$, intermediate $\left(0<e^{-\beta}<1\right)$ or absent $\left(e^{-\beta}=0\right)$ memory; for convenience, we refer to this term throughout as 'memory'.

The subjective quality $q(0 \leq q \leq 1)$ of different locations in the landscape is a function of the perceived and/or memorised habitat characteristics, the animal's current state and its travelling propensity, modelled here as $e^{-\gamma d_{i}}$, where the 'friction' coefficient $\gamma(\gamma \geq 0)$ (sensu Avgar et al. 2013) models how far the animal is willing or able to travel by reducing the 
attractiveness of all landscape features as a function of distance. State affects the relative importance given to each landscape layer, such that for low values of $s$ higher relative importance is given to the vegetation (food-containing) layer, and when $s$ is high greater relative importance is given to the background layer. The subjective quality of a cell is therefore given by

$q_{i, t}=\left(m_{i, 1, t} s_{t}+m_{i, 2, t}\left(1-s_{t}\right)\right) e^{-\gamma d_{i}}$.

When applied to all cells, the resulting map is the subjective landscape; the landscape as it is viewed from the animal's perspective at a particular point in space and time (Avgar et al. 2013).

\section{Movement}

At each time step, the animal can choose to either remain in its current cell or move to one of the six (equidistant) adjacent cells. Specifically, animal movement behaviour was modelled as a series of discrete probabilistic decisions, based on attraction to specific cells within the animal's subjective landscape: the preference for remaining in the current cell, $k$, is given by $q_{k, t}$; the preference for moving to a particular adjacent cell is given as the maximum value of all cells in the subjective landscape within a $60^{\circ}$ cone centred on the direction of that cell. To ensure a correlated random walk in relatively homogeneous landscapes, these preferences are then multiplied by the probability of moving in a given direction drawn from a von Mises distribution with a mean direction $\left(\mu_{m}\right)$, which is equal to the current direction of travel, and concentration parameter $\kappa_{m}$. These combined preferences are then re-scaled so they sum to unity, giving the probability of moving to a given cell.

\section{Feeding, gut passage and seed dispersal}

Having entered a cell, the animal will feed if that cell contains vegetation. The amount of food consumed, $f$, is proportional to the value of the vegetative layer of the occupied cell, $k$, scaled by the animal's state at the previous time step (such that relatively hungry animals will eat proportionally more than relatively sated animals)

$f_{t}=A_{k, 2}\left(1-s_{t-1}\right)$.
It is assumed that all ingested food contains seeds, and that these are added to the animal's 'gut matrix', $\mathbf{G}=\left[g_{t}\right]$ (sensu D'hondt and Hoffmann 2011), where $g_{t}$ holds information on the amount of seeds ingested at each time step. For simplicity, we assume that the proportion of seeds ingested, and their probability of being destroyed through destruction and/or digestion, is fixed; the number of viable seeds available for excretion when the animal defecates is therefore directly proportional to the total amount of food eaten (i.e. $f_{t} \sim g_{t}$ ).

At each time step, the animal defecates with a probability drawn from a cumulative lognormal probability density function, defined by the location parameter $\mu_{d}$ and the scale parameter $\sigma_{d}$, such that the probability of defecation increases with time since the last defecation event (D'hondt and Hoffmann 2011). Such a distribution has been shown to provide good fits to empirical gut passage data (e.g. Rawsthorne et al. 2009; D'hondt and Hoffmann 2011). If there are seeds present in the gut at the time of defecation, a proportion of these are excreted. This proportion is determined by the time that has passed since their ingestion, modelled as the cumulative lognormal probability density function defined by the location parameter $\mu_{s}$ and scale parameter $\sigma_{s}$.

Food consumption also affects the animal's state. State decreases over time as a function of the hunger coefficient $\lambda(0 \leq \lambda \leq 1)$, which encapsulates the nonlinear relationship between food intake and hunger, and increases as a function of food consumed, scaled by the satiation coefficient $\kappa(0 \leq \kappa \leq 1)$, such that

$s_{t}=\lambda s_{t-1}+\kappa f_{t}$.

\section{Model parameterisation}

We parameterised two types of model. The first was parameterised with arbitrary values in order to explore the generic impact of memory on seed dispersal in landscapes with one or two plants, and with one forager. The second was parameterised using data on the behaviour and memory of red-footed tortoises $(\mathrm{Ch}$ elonoidis carbonaria) in simulated natural landscapes in order to explore the specific impact of landscape use (in particular, the use of gaps in the forest canopy as basking spots) on the pattern of seed dispersal. 
In the first set of models, landscapes consisted of a $40 \times 40$ hexagonal grid. The background layer was generated as a Gaussian random field (with radius $=10$; sensu Kroese and Botev 2013), while the vegetative layer contained either a single plant (occupying a single cell) located at the centre of the landscape or two plants located at a fixed distance of 20 hexagons apart (two-plant model). In the models with a single plant, it was given a fixed value of 1 ; in the two-plant model, the values were randomly drawn from a uniform distribution in the interval $[0,1]$ to simulate variation in the quantity of food available at each location. All other cells in the vegetative layer were set to zero. An animal's memory was initially set to 0 and its state to 0.5 (i.e. when $t=1, m_{i, j, t-1}=0$ in Eq. 2, and $\left.s_{t}=0.5\right)$. The value of the memory decay coefficient $\beta$ was either drawn randomly from an exponential-logarithmic distribution with shape parameter $r=0.99$ and scale parameter $b=1$, which generates values in the interval $[0, \infty$ ) (and hence the values of the term $e^{-\beta}$ uniformly distributed in the interval $[0,1]$ ) or fixed at either 0 or $\infty$. The values of other model parameters were as follows: $\alpha=0.5$, $\gamma=0.07, \quad \kappa=0.1, \quad \lambda=0.99, \quad \mu_{d}=4, \quad \sigma_{d}=0.2$, $\mu_{s}=1, \sigma_{s}=0.2$ and $\kappa_{m}=1.83$. While these values are arbitrary, varying them had little qualitative impact on the results presented here and so they are fixed for simplicity. Each animal started the simulation occupying the same cell as one of the plants, which precluded an initial search period and endowed all animals with comparable starting memory. The model was run over $T=10,000$ time steps.

In the second set of models, two types of landscape were simulated, termed 'closed canopy' and 'deforested'. In each, the background layer was based on a binarised [0 or 1] Gaussian random field (generated using the 'gstat' package for R; Pebesma 2004) represented as a $100 \times 100$ hexagonal grid. The centre-to-apex distance of each hexagon was assumed to represent $1 \mathrm{~m}$ of landscape and so the total dimensions of each landscape correspond to 1 ha, which is consistent with the maximum area known to be traversed by red-footed tortoises in a month (Guzmán and Stevenson 2008). The simulated dimensions and frequency of gaps in the closed canopy landscape, and the proportion of hexagons occupied by adult plants in both landscapes, were based on data collected for a region of neotropical rainforest located between Esmeraldas and Imbabura Provinces in Ecuador $\left(79^{\circ} 02^{\prime} 756^{\prime \prime}\right.$ West, $0^{\circ} 20^{\prime} 867^{\prime \prime}$ north), and known to be inhabited by red-footed tortoises (Mariscal Chavez 2016). Each time step was assumed to correspond to $1 \mathrm{~min}$ of real time, and so based on recorded tortoise movement and daily activity patterns (Moskovits and Bjorndal 1990; Guzmán and Stevenson 2008), setting $T=10,000$ time steps would equate to one month of tortoise activity. We set $\beta=0.99$, which results in a rate of memory decay consistent with that observed in experiments with captive tortoises (Soldati 2015); all other parameter values were the same as those used in the first set of models.

\section{Data analysis}

The following data were collected for each run of the model: (i) the total amount of seeds dispersed (i.e. the sum of all seeds deposited at each spatial location in the landscape; arbitrary units), (ii) the median seed dispersal distance (median hexagonal Manhattan distance from the plant's location) and (iii) the number of times the plant was visited per 10,000 time steps. We also collected data on disperser survival by assuming that if an animal's state fell below a threshold of 0.001 they had 'died'. Differences between these measures as a function of memory (i.e. the term $e^{-\beta}$ in Eq. 1) were tested using general linear models or, in the case of disperser survival, survival analysis. All statistical analyses were conducted using $\mathrm{R}$ version 2.15.2 ( $\mathrm{R}$ Core Development Team 2013).

\section{References}

Aparicio A, Berens DG, Müller J, Farwing N (2013) Resources determine frugivore assemblages and fruit removal along an elevation gradient. Acta Oecol 52:45-49

Avgar T, Deardon R, Fryxell JM (2013) An empirically parameterized individual based model of animal movement, perception, and memory. Ecol Model 251:158-172

Ban SD, Boesch C, Janmaat KRL (2014) Taï chimpanzees anticipate revisiting high-valued fruit trees from further distances. Anim Cognit 17:1353-1364

Bekoff M, Allen C, Grant MC (1999) Feeding decisions by Steller's jays (Cyanocitta stelleri): the utility of a logistic regression model for analyses of where, what, and with whom to eat. Ethology 105:393-406 
Biebach H, Gordijn M, Krebs JR (1989) Time-and-place learning by garden warblers, Sylvia borin. Anim Behav 37:353-360

Blake S, Inkamba-Nkulu C (2004) Fruit, minerals and forest elephant trails: do all roads lead to Rome? Biotropica 36:392-401

Blake S, Deem SL, Mossimbo E, Maisels F, Walsh P (2009) Forest elephants: tree planters of the Congo. Biotropica 41:459-468

Bond AB, Cook RG, Lamb MR (1981) Spatial memory and the performance of rats and pigeons in the radial-arm maze. Anim Learn Behav 9:575-580

Bonte D, Van Dyck H, Bullock JM, Coulon A, Delgado M et al (2011) Costs of dispersal. Biol Rev 87:290-312

Boyer D, López-Corona O (2009) Self-organization, scaling and collapse in a coupled automaton model of foragers and vegetation resources with seed dispersal. J Phys A Math Theor 42:43014

Boyer D, Walsh P (2010) Modelling the mobility of living organisms in heterogeneous landscapes: does memory improve foraging success? Philos Trans R Soc A 368:5645-5659

Bracis C, Gurarie E, Van Moorter B, Goodwin RA (2015) Memory effects on movement behaviour in animal foraging. PLoS One. doi:10.1371/journal.pone.0136057

Buckley YM, Anderson S, Catterall CP, Corlett RT, Engel T, Gosper CR, Nathan R, Richardson DM, Setter M, Spiegel O, Vivian-Smith G, Voigt FA, Weir JES, Wwescott DA (2006) Management of plant invasions mediated by frugivore interactions. J Appl Ecol 43:848-857

Burns JG, Foucaud J, Mery F (2011) Costs of memory: lessons from 'mini' brains. Proc R Soc B 278:923-929

Calviño-Cancela M, Martín-Herrero J (2009) Effectiveness of a varied assemblage of seed dispersers of a fleshy-fruited plant. Ecology 90:3503-3515

Carlo TA, Morales JM (2008) Inequalities in fruit-removal and seed dispersal: consequences of bird behaviour, neighbourhood density and landscape aggregation. J Ecol 96:609-618

Cazetta E, Schaefer HM, Galetti M (2009) Why are fruits colorful? The relative importance of achromatic and chromatic contrasts for detection by birds. Evol Ecol 23:233-244

Cazetta E, Galetti M, Rezende EL, Schaefer HM (2012) On the reliability of visual communication in vertebrate- dispersed fruits. J Ecol 100:277-286

Chapman CA, Chapman LJ, Struhsaker TT, Zanne AE, Clark CJ, Poulsen JR (2005) A long-term evaluation of fruiting phenology: importance of climate change. J Trop Ecol 21:31-45

Corbet SA, Delfosse ES (1984) Honeybees and the nectar of Echium plantagineum L. in Southeastern Australia. J Comp Physiol A 9:125-139

Cordeiro NJ, Howe HF (2003) Forest fragmentation severs mutualism between seed dispersers and an endemic African tree. P Natl Acad Sci USA 100:14052-14056

Corlett RT (2011) How to be a frugivore (in a changing world). Acta Oecol 37:674-681

Corlett RT, Lafrankie JV (1998) Potential impacts of climate change on tropical Asian forests through an influence on phenology. Clim Change 39:439-453
Cousens RD, Hill J, French K, Bishop ID (2010) Towards better prediction of seed dispersal by animals. Funct Ecol 24:1163-1170

D'hondt B, Hoffmann M (2011) A reassessment of the role of simple seed traits in mortality following herbivore ingestion. Plant Biol 13:118-124

Daan S, Koene P (1981) On the timing of foraging flights by oystercatchers, Haematopus ostralegus, on tidal mudflats. Neth J Sea Res 15:1-22

Dale RHI, Innis NK (1986) Interactions between response stereotypy and memory strategies on the eight-arm radial maze. Behav Brain Res 19:17-25

Di Fiore A, Suarez SA (2007) Route-based travel and shared routes in sympatric spider and woolly monkeys: cognitive and evolutionary implications. Anim Cognit 10:317-329

Dominy NJ, Lucas PW, Osorio D, Yamashita N (2001) The sensory ecology of primate food perception. Evol Anthropol 10:171-186

Dominy NJ, Garber PA, Bicca-Marques JC, Azevedo-Lopes MA (2003) Do female tamarins use visual cues to detect fruit rewards more successfully than do males? Anim Behav 66:829-837

Eliassen S, Jorgensen C, Mangel M, Giske J (2009) Quantifying the adaptive value of learning in foraging behaviour. Am Nat 174:478-489

Fagot J, Cook RG (2006) Evidence for large long-term memory capacities in baboons and pigeons and its implications for learning and the evolution of cognition. P Natl Acad Sci USA 103:17564-17567

Fleming TH, Kress JW (2011) A brief history of fruits and frugivores. Acta Oecol 37:521-530

Fleming TH, Breitwisch R, Whitesides GH (1987) Patterns of tropical vertebrate frugivore diversity. Annu Rev Ecol Syst 18:91-109

Foley C, Pettorelli N, Foley L (2008) Severe drought and calf survival in elephants. Biol Lett 4:541-544

Fragoso JMV, Silvius KM, Correa JA (2003) Long-distance seed dispersal by tapirs increases seed survival and aggregates tropical trees. Ecology 84:1998-2006

Galetti M, Dirzo R (2013) Ecological and evolutionary consequences of living in a defaunated world. Biol Conserv 163:1-6

Garcia D, Martinez D, Herrera JM, Morales JM (2013) Functional heterogeneity in a plant-frugivore assemblage enhances seed dispersal resilience to habitat loss. Ecography 36:197-208

Gleditsch JM, Carlo TA (2011) Fruit quantity of invasive shrubs predicts the abundance of common native avian frugivores in central Pennsylvania. Divers Distrib 17:244-253

González-Castro A, Calviño-Cancela M, Nogales M (2015) Comparing seed dispersal effectiveness by frugivores at the community level. Ecology 96:808-818

Gopukumar N, Nathan PT, Doss PS, Prakash A, Emmanuel K, Balasingh J, Marimuthu G, Kunz TH (2003) Early ontogeny of foraging behavior in the short-nosed fruit bat Cynopterus sphinx (Megachiroptera): preliminary results. Mammalia 67:139-145

Gosset D, Roeder JJ (2000) Colour and shape discrimination in black lemurs (Eulemur macaco). Folia Primatol 71:173-176 
Griffiths CJ, Jones CG, Hansen DM, Puttoo M, Tatayah RV, Müller CB, Harris S (2010) The use of extant nonindigenous tortoises as a restoration tool to replace extinct ecosystem engineers. Restor Ecol 18:1-7

Guzmán A, Stevenson PR (2008) Seed dispersal, habitat selection and movement patterns in the Amazonian tortoise Geochelone denticulata. Amphib-Reptil 29:463-472

Guzmán A, Stevenson PR (2011) A new hypothesis for the importance of seed dispersal in time. Rev Biol Trop 59:1795-1803

Hansen DM, Donlan CJ, Griffiths CJ, Campbell KJ (2010) Ecological history and latent conservation potential: large and giant tortoises as a model for taxon substitutions. Ecography 33:272-284

Harms KE, Wright SJ, Calderon O, Hernandez A, Herre EA (2000) Pervasive density-dependent recruitment enhances seedling diversity in a tropical forest. Nature 404:493-495

Henderson J, Hurly TA, Bateson M, Healy SD (2006) Timing in free-living rufous hummingbirds, Selasphorus rufus. Curr Biol 16:512-515

Howe HF (1984) Implications of seed dispersal by animals for tropical reserve management. Biol Conserv 30:261-281

Howe HF, Miriti MN (2000) No question: seed dispersal matters. Trends Ecol Evol 15:434-436

Howe HF, Smallwood J (1982) Ecology of seed dispersal. Annu Rev Ecol Syst 13:201-228

Hübener F, Laska M (2001) A two-choice discrimination method to assess olfactory performance in pigtailed macaques, Macaca nemestrina. Physiol Behav 72:511-519

Janmaat KRL, Chancellor R (2010) Exploring new areas. How important is long-term spatial memory for mangabey (Lophocebus albigena johnstonii) foraging efficiency? Int J Primatol 31:863-866

Janmaat KRL, Byrne RW, Zuberbuhler K (2006) Primates take weather into account when searching for fruits. Curr Biol 16:1232-1237

Janmaat KRL, Ban SD, Boesch C (2013) Chimpanzees use long term spatial memory to monitor large fruit trees and remember feeding experiences across seasons. Anim Behav 6:1183-1205

Janmaat KRL, Polansky L, Dagui Ban S, Boesch C (2014) Wild chimpanzee plan their breakfast time, type and location. P Natl Acad Sci USA 111:16343-16348

Janzen DH (1970) Herbivores and the number of tree species in tropical forests. Am Nat 104:501-528

Jerozolimski A, Ribeiro MBN, Martins M (2009) Are tortoises important seed dispersers in Amazonian forests? Oecologia 161:517-528

Jordano P (2000) Fruits and frugivory. In: Fenner M (ed) Seeds: the ecology of regeneration in plant communities, 2 nd edn. CABI, Wallingford

Jordano P, Bascompte J, Olesen JM (2003) Invariant properties in coevolutionary networks of plant-animal interactions. Ecol Lett 6:69-81

Jordano P, García C, Godoy JA, García-Castaño JL (2007) Differential contribution of frugivores to complex seed dispersal patterns. P Natl Acad Sci USA 104:3278-3282

Kacelnik A, Bateson M (1996) Risky theories-the effect of variance on foraging decisions. Am Zool 36:402-434

Kacelnik A, Houston AI (1984) Some effects of energy cost on foraging strategies. Anim Behav 32:609-614
Kacelnik A, Krebs JR, Ens B (2013) Foraging in a changing environment: an experiment with starlings (Sturnus vulgaris). In: Commons ML, Kalcenik A, Shettleworth SJ (eds) Foraging: quantitative analysis of behaviour. Lawrence Erlbaum Associates, New Jersey

Kelber A, Vorobyev M, Osorio D (2007) Animal colour vision behavioural tests and physiological concepts. Biol Rev 78:81-118

Kroese DP, Botev ZI (2013) Spatial process generation. arXiv:1308.0399 [stat.CO]

Levey DJ, Moermond TC, Sloan Denslow J (1984) Fruit choice in neotropical birds: the effect of distance between fruits on preference patterns. Ecology 65:844-850

Link A, Di Fiore A (2006) Seed dispersal by spider monkeys and its importance in the maintenance of neotropical rain-forest diversity. J Trop Ecol 22:235-246

Lomáscolo SB, Schaefer HM (2010) Signal convergence in fruits: a result of selection by frugivores? J Evol Biol 23:614-624

López JC, Gómez Y, Rodríguez F, Broglio C, Vargas JP, Salas C (2001) Spatial learning in turtles. Anim Cognit 4:49-59

Mariscal Chavez AG (2016) Local baseline knowledge for conservation and restoration of degraded ecoystems in Ecuador. Thesis Acta Universitatis agriculturae Sueciae 2016:69

McCaughey SA, Tordoff MG (2002) Magnesium appetite in the rat. Appetite 38:29-38

Mendl M, Burman O, Laughlin K, Paul e (2001) Animal memory and animal welfare. Anim Welf 10:S141-S159

Mery F, Kawecki TJ (2005) A cost of long- term memory in drosophila. Science 308:1148

Momose K (2004) Plant reproductive interval and population density in aseasonal tropics. Ecol Res 19:245-253

Moore D, Van Nest BN, Seier E (2011) Diminishing returns: the influence of experience and environment on time-memory extinction in honey bee foragers. J Comp Physiol A 197:641-651

Moskovits DK, Bjorndal KA (1990) Diet and food preferences of the tortoises Geochelone carbonaria and G. denticulata in northwestern Brazil. Herpetologica 46:207-218

Moskovits DK, Kiester AR (1987) Activity levels and ranging behaviour of the two Amazonian tortoises, Geochelone carbonaria and Geochelone denticulata, in north-western. Funct Ecol 3:203-214

Muller-Landau HC, Hardesty BD (2005) Seed dispersal of woody plants in tropical forests: concepts, examples and future directions. In: Burslem D, Pinard M, Hartley S (eds) Biotic interactions in the tropics: their role in the maintenance of species diversity. Ecological reviews. Cambridge University Press, Cambridge

Murphy ME, King JR (1987) Dietary discrimination by molting white-crowned sparrows given diets differing only in sulphur amino acid concentrations. Physiol Zool 60:279-289

Normand E, Ban SD, Boesch C (2009) Forest chimpanzees (Pan troglodytes verus) remember the location of numerous fruit trees. Anim Cognit 12:797-807

Noser R, Byrne RW (2010) How do wild baboons (Papio ursinus) plan their routes? Travel among multiple highquality food sources with inter-group competition. Anim Cognit 13:145-155 
O'Keefe J, Nadel L (1978) The hippocampus as a cognitive map. Clarendon Press, Oxford

Pebesma EJ (2004) Multivariable geostatistics in S: the gstat package. Comput Geosci 30:683-691

Polansky L, Kilian W, Wittemyer G (2015) Elucidating the significance of spatial memory on movement decisions by African savannah elephants using state-space models. Proc R Soc B 282:20143042

Porter LM, Garber PA (2013) Foraging and spatial memory in wild Weddell's saddleback tamarins (Saguinus fuscicollis weddelli) when moving between distant and out-of-sight goals. Int J Primatol 34:30-48

Pyke G (1984) Optimal foraging theory: a critical review. Annu Rev Ecol Syst 15:523-575

R Core Development Team (2013) R: a language and environment for statistical computing. R Foundation for Statistical Computing. Vienna, Austria. https://www.R-project.org/

Rawsthorne J, Roshier DA, Murphy SR (2009) A simple parametric method for reducing sample sizes in gut passage time trials. Ecology 90:2328-2331

Roberts W (2002) Are animals stuck in time? Psychol Bull 128:473-489

Robledo-Arnuncio JJ, Klein EK, Muller-Landau C, Santamaria L (2014) Space, time and complexity in plant dispersal ecology. Mov Ecol 2:16. doi:10.1186/s40462-014-0016-3

Saracco JF, Collazo JA, Groom MJ (2004) How do frugivores track resources? Insights from spatial analyses of bird foraging in a tropical forest. Oecologia 139:235-245

Schaefer HM (2011) Why fruits go to the dark side. Acta Oecol 37:604-610

Schaefer HM, Schmidt V, Winkler H (2003) Testing the defence trade-off hypothesis: how content of nutrient and secondary compound affect fruit removal. Oikos 102:318-328

Schaefer HM, Schaefer V, Levey D (2004) How plant- animal interactions signal new insights in communication. Trends Ecol Evol 19:577-584

Schaefer HM, Spitzer K, Bairlein F (2008) Long-term effects of previous experience determine nutrient discrimination abilities in birds. Front Zool 5:4. doi:10.1186/1742-99945-4

Schupp EW (1993) Quantity, quality and the effectiveness of seed dispersal by animals. Vegetatio 107(108):15-29

Schupp EW, Jordano P (2010) The full path of Janzen-Connell effects: genetic tracking of seeds to adult plant recruitment. Mol Ecol 19:3953-3955

Schupp EW, Jordano P, Gómez JM (2010) Seed dispersal effectiveness revisited: a conceptual review. New Phytol 188:333-353

Siemers BM, Goerlitz HR, Robsomanitrandrasana E, Piep M, Ramanamanjato JB, Rakotondravony D, Ramilijaona O, Ganzhorn JU (2007) Sensory basis of food detection in wild Microcebus murinus. Int J Primatol 28:291-304

Soldati F (2015) Animal cognition meets ecosystem ecology: the impact of cognition on seed dispersal. Ph.D. thesis, University of Lincoln
Strong JN, Fragoso JMV (2006) Seed Dispersal by Geochelone carbonaria and Geochelone denticulata in Northwestern Brazil. Biotropica 38:683-686

Tanner EVJ (1982) Species diversity and reproductive mechanisms in Jamaican trees. Biol J Linn Soc 18:263-278

Tellería JL, Pérez-Tris J (2003) Seasonal distribution of a migratory bird: effects of local and regional resource tracking. J Biogeogr 30:1583-1591

Tellería JL, Ramírez A, Pérez-Tris J (2008) Fruit tracking between sites and years by birds in Mediterranean wintering grounds. Ecography 31:381-388

Traveset A, Heleno R, Nogales M (2014) The ecology of seed dispersal. In: Gallagher RS (ed) Seeds: the ecology of regeneration in plant communities, 3rd edn. CABI Publishing, Wallingford

Tsuji Y, Shimoda-Ishiguro M, Ohnishi N, Takatsuki S (2007) A friend in need is a friend indeed: feeding association between Japanese macaques and sika deer. Acta Theriol 52:e427-e434

Wang BC, Smith TB (2002) Closing the seed dispersal loop. Trends Ecol Evol 17:379-385

Werner SJ, Kimball BA, Provenza FD (2008) Food color, flavor, and conditioned avoidance among red-winged blackbirds. Physiol Behav 93:110-117

Westcott DA, Bentrupperbaümer J, Bradford MG, McKeown A (2005) Incorporating patterns of disperser behaviour into models of seed dispersal and its effects on estimated dispersal curves. Oecologia 146:57-67

Wilkinson A, Huber L (2012) Cold-blooded cognition: reptilian cognitive abilities. In: Shackelford KT, Vonk J (eds) The oxford handbook of comparative evolutionary psychology. Oxford Library of Psychology, Oxford

Wilkinson A, Coward S, Hal G (2009) Visual and responsebased navigation in the tortoise (Geochelone carbonaria). Anim Cognit 12:779-787

Wilkinson A, Kuenstner K, Mueller J, Huber L (2010) Social learning in a nonsocial reptile. Biol Lett 6:614-616

Wills C, Condit R, Foster RB, Hubbell SP (1997) Strong density-and diversity-related effects help to maintain tree species diversity in a neotropical forest. P Natl Acad Sci USA 94:1252-1257

Wunderle JM Jr (1997) The role of animal seed dispersal in accelerating forest regeneration on degraded tropical lands. For Ecol Manag 99:223-235

Yarmolinsky DA, Zuker CS, Ryba NJP (2009) Common sense about taste: from mammals to insects. Cell 139:234-244

Yearsley JM, Villalba JJ, Gordon IJ, Kyriazakis I, Speakman JR, Tolkamp BJ, Illius AW, Duncan AJ (2006) A theory of associating food types with their postingestive consequences. Am Nat 167:705-716 